Journal of

Synchrotron

Radiation

ISSN 0909-0495

Received 2 May 2010

Accepted 20 August 2010

\section{Structure of the inhibitor complex of old yellow enzyme from Trypanosoma cruzi}

\author{
Keishi Yamaguchi, ${ }^{\mathrm{a}}$ Naoki Okamoto, ${ }^{\mathrm{a}}$ Keiji Tokuoka, ${ }^{\mathrm{a}}$ Shigeru Sugiyama, \\ Nahoko Uchiyama, ${ }^{b}$ Hiroyoshi Matsumura, ${ }^{a}$ Koji Inaka, ${ }^{c}$ Yoshihiro Urade $^{d}$ and \\ Tsuyoshi Inoue ${ }^{\mathrm{a} *}$ \\ a Department of Applied Chemistry, Graduate School of Engineering, Osaka University,

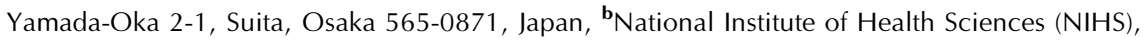 \\ Tokyo 158-8501, Japan, 'MARUWA Foods and Biosciences, Tsutsui-cho 170-1, Yamatokoriyama, \\ Nara 639-1123, Japan, and ${ }^{\mathrm{d} D e p a r t m e n t}$ of Molecular Behavior Biology, Osaka Bioscience \\ Institute, Osaka 565-0874, Japan. E-mail: inouet@chem.eng.osaka-u.ac.jp
}

\begin{abstract}
Old yellow enzyme (OYE) is an NADPH oxidoreductase which contains flavin mononucleotide as prosthetic group. The X-ray structures of OYE from Trypanosoma cruzi (TcOYE) which produces prostaglandin ( $\mathrm{PG}$ ) $\mathrm{F}_{2 \alpha}$ from $\mathrm{PGH}_{2}$ have been determined in the presence or absence of menadione. The binding motif of menadione, known as one of the inhibitors for TcOYE, should accelerate the structure-based development of novel anti-chagasic drugs that inhibit $\mathrm{PGF}_{2 \alpha}$ production specifically.
\end{abstract}

Keywords: X-ray structure; inhibitor complex; prostaglandin synthase.

\section{Introduction}

Prostaglandin (PG) $\mathrm{F}_{2 \alpha}$ synthase (PGFS) is the enzyme which produces $\mathrm{PGF}_{2 \alpha}$ from the $\mathrm{PGH}_{2}$, and was first isolated from mammals (Watanabe et al., 1985). Mammalian PGFSs belong to aldo-ketoreductases (Bohren et al., 1989; Bruce et al., 1994), which are NAD(P)(H)-dependant oxidoreductase. In mammals, $\mathrm{PGF}_{2 \alpha}$ is a potent mediator of various physiological processes (Narumiya et al., 1999; Glew, 1992; Samuelsson, 1979) including vasculartone, constriction of uterine muscle (Bygdeman et al., 1970) and pulmonary arteries (Oliw et al., 1983; Mathe et al., 1977), and induction of luteolysis during the estrous cycle and prior to parturition (Horton \& Poyser, 1976; McCracken et al., 1972). During pathological processes in mammals, $\mathrm{PGF}_{2 \alpha}$ overproduction causes ovarian dysfunction and miscarriage (Dubois et al., 1998; Mutayoba et al., 1989; Davies et al., 1984).

$\mathrm{PGF}_{2 \alpha}$ is produced not only in mammals but also in parasitic protozoa which causes serious infections, such as Plasmodium falciparum (Kubata et al., 1998), Trypanosoma brucei (Kubata et al., 2000; Okano et al., 2002; Kilunga et al., 2005) and Leishmania major (Kabututu et al., 2002, 2003). Owing to their identification, pathological relationships of parasitic PGFSs with human disease have begun to emerge. For example, it is thought that PGFS from Trypanosoma brucei (TbPGFS) plays a role in pathogenesis trypanosomiasis because African trypanosomiasis is characterized by miscarriage owing to $\mathrm{PGF}_{2 \alpha}$ overproduction correlated with parasitemia peaks (Mutayoba et al., 1989). Therefore, the study of parasitic PGFS is quite significant because it can lead to investigation of the pathological roles and development of the inhibitor of PGFS for remedies.

Chagas disease, caused by Trypanosoma cruzi, affects more than 20 million people and poses a major public health and economic problem in South America (World Health Organization, 1990). This situation has been worsened by the lack of effective vaccines and undesirable side effects of anti-chagasic drugs, such as nifurtimox and benznidazole (Aldunate \& Morello, 1993; Henderson et al., 1988; Docampo \& Moreno, 1986; Docampo, 1990), in addition to the emergence of parasite resistance to these drugs. Therefore, the development of a new chemotherapeutic treatment is an urgent need.

PGFS from $T$. cruzi was identified by Kubata et al. and it was found that this enzyme belonged to old yellow enzyme (OYE) (Kubata et al., 2002). OYE was originally isolated from brewers' bottom yeast in the 1930s, and the first protein requiring a vitamin $\mathrm{B}_{2}$-derived molecule, flavin mononucleotide (FMN), of its catalysis (Warburg, 1933; Schopfer \& Massey, 1991). The previously detected OYE families from bacteria (Warburg, 1933; Matthews \& Massey, 1969), yeast (Schaller \& Weiler, 1997) and plants (French et al., 1996; Blehert et al., 1999) are able to reduce a variety of compounds, such as unsaturated aldehydes and ketones (French \& Bruce, 1994; Vaz et al., 1995), nitro-esters (French et al., 1996; Snape et al., 1997; Blehert et al., 1999; Meah \& Massey, 2000) and nitroaromatic substrates (French et al., 1998; Pak et al., 2000; Williams et al., 2004).

OYE from $T$. cruzi (TcOYE) catalyzes prostaglandin $\mathrm{F}_{2 \alpha}$ synthesis (Fig. 1) as well as the reduction of many kinds of trypanocidal drugs, such as naphtoquinone and nitrohetero- 


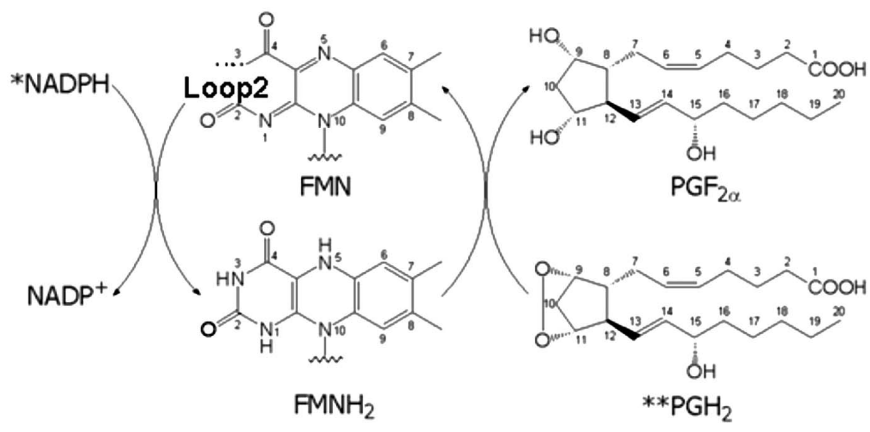

Figure 1

Reduction of $\mathrm{PGH}_{2}$ to $\mathrm{PGF}_{2 \alpha}$ by TcOYE. FMN (cofactor of TcOYE) is reduced to $\mathrm{FMNH}_{2}$ by intravital nicotinamide adenine dinucleotide phosphate $(\mathrm{NADPH})$, and the product $\mathrm{PGF}_{2 \alpha}$ is subsequently generated by $\mathrm{FMNH}_{2}$.

cyclic compounds (Kubata et al., 2002). By electron spin resonance it was found that these compounds can undergo either one- or two-electron reduction. Naphtoquinone, such as menadione $\left(K_{\mathrm{m}}=0.82 \mu M\right)$ or $\beta$-lapachone $\left(K_{\mathrm{m}}=0.17 \mu M\right)$, is reduced by one-electron reduction, generating semiquinone radicals which cause the cell death in susceptible parasites, while nitroheterocyclic compounds, such as 4-nitroquinoline$N$-oxide $\left(K_{\mathrm{m}}=9.5 \mu M\right)$ or nifurtimox $\left(K_{\mathrm{m}}=19.0 \mu M\right)$, are reduced by two-electron reduction (Kubata et al., 2002). Therefore, three-dimensional information of the structure in complex with the quinine compounds is valuable for the design of novel anti-chagasic drugs by which semiquinone radicals are more efficiently generated in $T$. cruzi.

Here we report the first X-ray structures of TcOYE which produces $\mathrm{PGF}_{2 \alpha}$ from $\mathrm{PGH}_{2}$ in the presence or absence of menadione. The structural analysis of TcOYE/FMN/menadione ternary complex has provided the binding motif of menadione at the active site. These structures are useful for further drug design for Chagas disease.

\section{Materials and methods}

\subsection{Protein expression and crystallization}

Chemicals were obtained from Sigma-Ardrich at the highest available purity. TcOYE was overexpressed in E. coli and purified, and TcOYE/FMN binary complex was crystallized according to previously reported methods (Kubata et al., 2002; Sugiyama et al., 2007). These crystals were flash-cooled in liquid nitrogen with cryo-protectant solution containing $3 \%$ $(v / v)$ 2-methyl-2,4-pentanediol. The X-ray diffraction data were obtained up to $1.70 \AA$ resolution at SPring- 8 beamline BL41XU. The diffraction data were processed and scaled using the program HKL2000 (Otwinowski \& Minor, 1997).

\subsection{Structure determination and refinement}

The structure of TcOYE was determined by molecular replacement with the program $A M o R e$ (Navaza, 2001) using the structure of morphinone reductase from Pseudomonas putida (Protein Data Bank code 1gwj) (Barna et al., 2002) as a search model. Crystallographic refinement was carried out with the program CNS (Brünger et al., 1998). The refinement procedure included simulated annealing, positional refinement, restrained temperature factor refinement, and maximum-likelihood algorithms as provided by the $C N S$ program. Electron density maps based on the coefficients of $2 F_{\mathrm{o}}-F_{\mathrm{c}}$ and $F_{\mathrm{o}}-F_{\mathrm{c}}$ were used to build the atomic models in Coot (Emsley \& Cowtan, 2004). Water molecules were inserted manually and then checked by inspecting the $F_{\mathrm{o}}-F_{\mathrm{c}}$ map. FMN (cofactor) and menadione (ligand) were refined using atomic parameters extracted from the HIC-UP server (Kleywegt \& Jones, 1998), and could be inserted into the clearly defined electron density model after some cycles of refinement.

\subsection{Preparation of TcOYE complexed with menadione}

In order to prepare the complex crystals with menadione, the crystals of the TcOYE/FMN complex were soaked in a menadione solution for $16 \mathrm{~h}$ and then the crystals were flash frozen in liquid nitrogen. The X-ray diffraction data were obtained up to $2.5 \AA$ resolution by using Ultrax18 (Rigaku). Data collection, structure determination and refinement were carried out by the same methods as described above.

\section{Results and discussion}

\subsection{Overall structure of TcOYE}

The structure of TcOYE/FMN binary complex was determined by molecular replacement methods using that of morphinone reductase (Barna et al., 2002) as the searching model and refined at $1.7 \AA$ resolution with final $R_{\text {cryst }} / R_{\text {free }}$ values of $18.5 \% / 23.2 \%$. Our crystallographic properties and refinement statistics of the structure are presented in Table 1.

TcOYE, like other members of the OYE family, folds into an $(\alpha / \beta)_{8}$ barrel in which the cylindrical core composed of eight parallel $\beta$-strands $(\beta 1-\beta 8)$ is surrounded by eight $\alpha$ helices $(\alpha 1-\alpha 8)$. In addition, an N-terminal $\beta$-hairpin (S1 and $\mathrm{S} 2)$ closes the bottom of the barrel and two extra helices (H1 and H2) lie in the loops connecting $\beta 4$ to $\alpha 4$ and $\beta 8$ to $\alpha 8$, respectively (Fig. 2). The loop regions from 105 to 165 (Loop 1) and 351 to 379 (Loop 2) exhibit the relatively higher $B$ factors of 21.3 and $18.8 \AA^{2}$, respectively, while the overall $B$ factor of TcOYE without those two loop ranges was calculated to be $13.1 \AA^{2}$. This difference in the $B$-factor shows the flexibility of these two loops.

\subsection{FMN binding site}

FMN is tightly bound at the C-terminal ends of the eight $\beta$ strands in the barrel and exhibits quite low $B$-factors (Fig. 3). Most amino acid residues which bind to the riboflavin moiety of FMN are highly conserved among the different known OYE structures, except Ala61. Ala61 in TcOYE was conserved as alanine or glycine among the known OYE structures; however, the amide nitrogen atom of the corresponding amino acid interacts with $\mathrm{O} 4$ of FMN. On the other hand, three residues bound to the phosphate $\mathrm{O}$ atoms in FMN are not conserved: the side chain of Asn313 and the main 
Table 1

Data collection and refinement statistics for TcOYE/FMN and TcOYE/ FMN/menadione.

Values in parentheses are for the highest resolution shell.

\begin{tabular}{lll}
\hline & TcOYE/FMN & TcOYE/FMN/menadione \\
\hline Beamline & SPring-8 BL41XU & Ultrax18 \\
Space group & $P 2_{1}$ & $P 2_{1}$ \\
Cell constants $\left(\AA{ }^{\circ}\right)$ & $a=56.29, b=78.79$, & $a=47.58, b=53.66$, \\
& \multicolumn{1}{c}{$c=78.80, \beta=93.37$} & \multicolumn{1}{c}{$c=120.00, \beta=90.004$} \\
Resolution range $(\AA)$ & $50.0-1.70(1.76-1.70)$ & $50.0-2.5(2.54-2.50)$ \\
No. of molecules per & 2 & 2 \\
$\quad$ asymmetric unit & & \\
$V_{\mathrm{M}}\left(\AA^{3} \mathrm{Da}^{-1}\right)$ & 2.1 & 1.8 \\
$V_{\text {solv }}(\%)$ & 41 & 35 \\
No. of measured & 424814 & 70984 \\
$\quad$ reflections & & \\
No. of unique & 75469 & 20908 \\
$\quad$ reflections & & \\
$I / \sigma(I)$ & 6.3 & 6.8 \\
$R_{\text {merge }}(\%) \dagger$ & $7.0(27.4)$ & $3.5(6.2)$ \\
Completeness $(\%)$ & $100.0(100.0)$ & $98.1(95.0)$ \\
$R_{\text {cryst }}(\%) \ddagger$ & 18.5 & 33.2 \\
$R_{\text {free }}(\%) \S$ & 23.2 & 40.9 \\
R.m.s. deviations & & 0.01 \\
$\quad$ Bonds $(\AA)$ & 0.005 & 1.7 \\
$\quad$ Angles $\left({ }^{\circ}\right)$ & 1.4 & \\
\hline & &
\end{tabular}

$\dagger R_{\text {merge }}=\Sigma|I(k)-I| / \Sigma I(k)$, where $I(k)$ is the value of the $k$ th measurement of the intensity of a reflection, $I$ is the mean value of the intensity of that reflection, and the summation is over all measurements. $\neq R_{\text {cryst }}=\Sigma|| F_{\mathrm{o}}|-| F_{\mathrm{c}}|/ \Sigma| F_{\mathrm{o}} \mid$, calculated from $90 \%$ of the data, which were used during the course of the refinement. $\S R_{\text {free }}=$ $\Sigma|| F_{\mathrm{o}}|-| F_{\mathrm{c}}|| / \Sigma\left|F_{\mathrm{o}}\right|$, calculated from $10 \%$ of the data, which were obtained during the course of the refinement.

chains of Leu314 and Lys338 interact with the phosphate O atoms through water molecules.

\subsection{The binding motif of menadione}

In order to develop more effective inhibitors we have solved the structure of TcOYE/FMN/menadione ternary complex at $2.5 \AA$ resolution (Table 1). The whole structure of TcOYE does not change even upon binding of menadione. The binding motif of menadione is defined in the difference

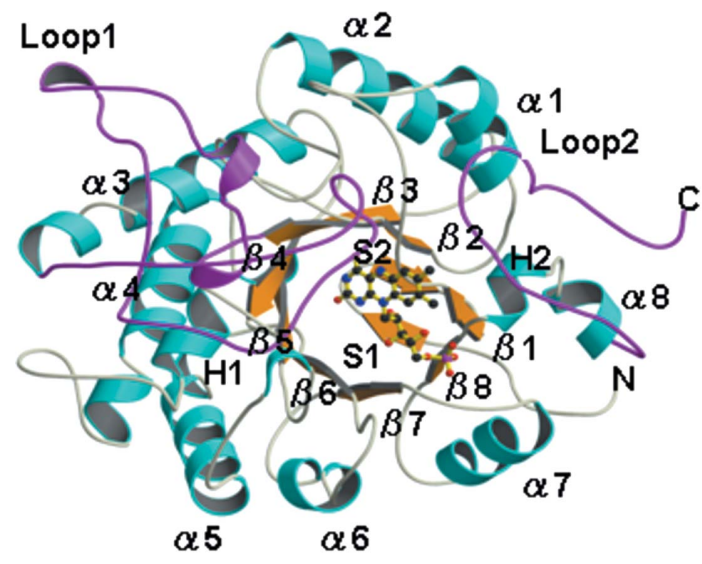

Figure 2

The overall structure of TcOYE. The $\alpha$-helices (cyan) and $\beta$-sheets (orange) are separated among them by loops (light yellow). Loop 1 and Loop 2 are shown in magenta. FMN is shown as a ball-and-stick model. The image was created by using MOLSCRIPT (Kraulis, 1991) and RASTER3D (Merritt \& Murphy, 1994).

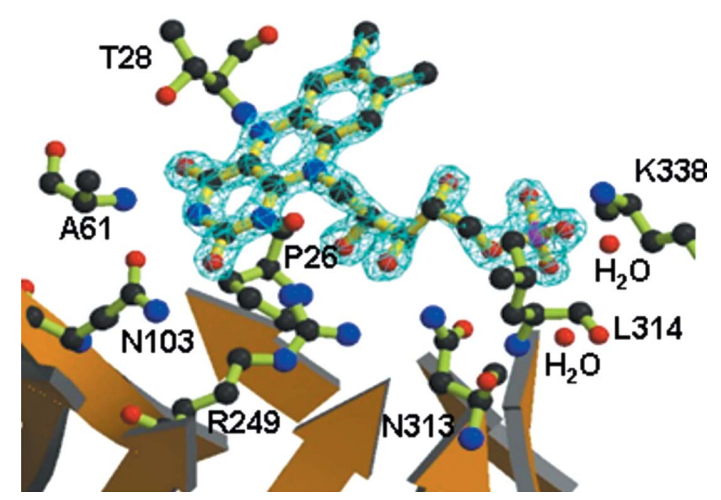

Figure 3

FMN binding model with $2 F_{\mathrm{o}}-F_{\mathrm{c}}$ omit map. The FMN electron density is calculated at $1.7 \AA$ and contoured at $2.5 \sigma$. $\mathrm{O}, \mathrm{N}$ and $\mathrm{P}$ atoms are shown in red, blue and magenta, respectively. Labelled residues indicate those involved in FMN binding. The figure was drawn using the programs MOLSCRIPT and RASTER3D.

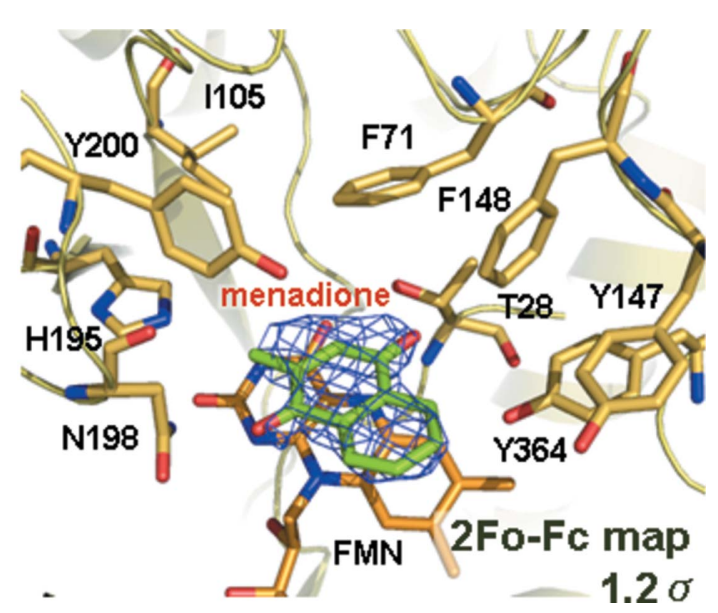

Figure 4

The binding site of menadione. Menadione (green) is positioned above the isoalloxazine ring of FMN. The menadione electron density is calculated at $2.5 \AA$ and contoured at $1.2 \sigma$. The figure was drawn using the program PyMOL (DeLano, 2005).

electron density maps even at low occupancy (Fig. 4). The cause of its low affinity $\left(K_{\mathrm{m}}=0.82 \mu M\right)$ is assumed to be because the ligand is stabilized by only a $\pi-\pi$ interaction with the isoalloxazien ring of FMN. To increase the affinity of menadione, interactions with His195, Asn198 or Tyr 364 should be designed in the future.

\section{Conclusion}

We have solved the structures of TcOYE in the presence or absence of menadione. The binding motif of the inhibitor at the active site of TcOYE has been elucidated from TcOYE/ FMN/menadione ternary complex. Future work is in progress to obtain the structure in complex with other inhibitors to elucidate the reaction mechanism of TcOYE in detail, which can be expected to lead to the development of heroic antichagasic drugs. 
The authors express their appreciation to Professor B. K. Kubata, Biosciences Eastern and Central Africa, and Dr Z. Kabututu, Osaka Bioscience Institute, for their early support of the protein expression. The authors are grateful to M. Yoshimura, M. Yamashita, E. Yamashita and A. Nakagawa at SPring-8 beamlines 12B2, 40B2 and 44XU for fundamental data collection, and to N. Shimizu and K. Hasegawa for their kind support during data collection at SPring- 8 beamline 41XU. This work was supported by Grants-in-Aid for Scientific Research (Nos. 16017260 and 18350086) from the Ministry of Education, Culture, Sports, Science and Technology of Japan and the PRESTO project, Japan Science and Technology Agency, the National Project on Protein Structural and Functional Analyses, Japan (to TI), and the Center of Excellence (21COE) program 'Creation of Integrated EcoChemistry of Osaka University' (to KT), and was partly supported by the Applied Research Pilot Project for the Industrial Use of Space promoted by JAXA and Japan Space Utilization Promotion Center (JSUP) and a grant from Japan Foundation for Applied Enzymology and Osaka City (to YU)

\section{References}

Aldunate, J. \& Morello, A. (1993). Free Radicals in the Mode of Action of Antiparasitic Drugs. Chur: Harwood Academic Publisher.

Barna, T., Messiha, H. L., Petosa, C., Bruce, N. C., Scrutton, N. S. \& Moody, P. C. (2002). J. Biol. Chem. 277, 30976-30983.

Blehert, D. S., Fox, B. G. \& Chambliss, G. H. (1999). J. Bacteriol. 181, 6254-6263.

Bohren, K. M., Bullock, B., Wermuth, B. \& Gabbay, K. H. (1989). J. Biol. Chem. 264, 9547-9551.

Bruce, N. C., Willey, D. L., Coulson, A. F. \& Jeffery, J. (1994). Biochem. J. 299, 805-811.

Brünger, A. T., Adams, P. D., Clore, G. M., DeLano, W. L., Gros, P., Grosse-Kunstleve, R. W., Jiang, J.-S., Kuszewski, J., Nilges, M., Pannu, N. S., Read, R. J., Rice, L. M., Simonson, T. \& Warren, G. L. (1998). Acta Cryst. D54, 905-921.

Bygdeman, M., Kwon, S. U., Mukherjee, T., Roth-Brandel, U. \& Wiqvist, N. (1970). Am. J. Obstet. Gynecol. 106, 567-572.

Davies, P., Bailey, P. J., Goldenberg, M. M. \& Ford-Hutchinson, A. W. (1984). Annu. Rev. Immunol. 2, 335-357.

DeLano, W. L. (2005). Drug. Discov. Today, 10, 213-217.

Docampo, R. (1990). Chem. Biol. Interact. 73, 1-27.

Docampo, R. \& Moreno, S. N. (1986). Fed. Proc. 45, 2471-2476.

Dubois, R. N., Abramson, S. B., Crofford, L., Gupta, R. A., Simon, L. S., Van De Putte, L. B. \& Lipsky, P. E. (1998). FASEB J. 12, $1063-$ 1073.

Emsley, P. \& Cowtan, K. (2004). Acta Cryst. D60, 2126-2132.

French, C. E. \& Bruce, N. C. (1994). Biochem. J. 301, 97-103.

French, C. E., Nicklin, S. \& Bruce, N. C. (1996). J. Bacteriol. 178, 6623-6627.

French, C. E., Nicklin, S. \& Bruce, N. C. (1998). Appl. Environ. Microbiol. 64, 2864-2868.

Glew, R. H. (1992). In Textbook of Biochemistry with Clinical Correlations, edited by Thomas M. Devlin. New York: Wiley-Liss.

Henderson, G. B., Ulrich, P., Fairlamb, A. H., Rosenberg, I., Pereira, M., Sela, M. \& Cerami, A. (1988). Proc. Natl. Acad. Sci. USA, 85, 5374-5378.

Horton, E. W. \& Poyser, N. L. (1976). Physiol. Rev. 56, 595-651.
Kabututu, Z., Martin, S. K., Nozaki, T., Kawazu, S., Okada, T., Munday, C. J., Duszenko, M., Lazarus, M., Thuita, L. W., Urade, Y. \& Kubata, B. K. (2002). Int. J. Parasitol. 32, 1693-1700.

Kabututu, Z., Martin, S. K., Nozaki, T., Kawazu, S., Okada, T., Munday, C. J., Duszenko, M., Lazarus, M., Thuita, L. W., Urade, Y. \& Kubata, B. K. (2003). Int. J. Parasitol. 33, 221-228.

Kilunga, K. B., Inoue, T., Okano, Y., Kabututu, Z., Martin, S. K., Lazarus, M., Duszenko, M., Sumii, Y., Kusakari, Y., Matsumura, H., Kai, Y., Sugiyama, S., Inaka, K., Inui, T. \& Urade, Y. (2005). J. Biol. Chem. 280, 26371-26382.

Kleywegt, G. J. \& Jones, T. A. (1998). Acta Cryst. D54, 1119-1131.

Kraulis, P. J. (1991). J. Appl. Cryst. 24, 946-950.

Kubata, B. K., Duszenko, M., Kabututu, Z., Rawer, M., Szallies, A., Fujimori, K., Inui, T., Nozaki, T., Yamashita, K., Horii, T., Urade, Y. \& Hayaishi, O. (2000). J. Exp. Med. 192, 1327-1338.

Kubata, B. K., Eguchi, N., Urade, Y., Yamashita, K., Mitamura, T., Tai, K., Hayaishi, O. \& Horii, T. (1998). J. Exp. Med. 188, $1197-$ 1202.

Kubata, B. K., Kabututu, Z., Nozaki, T., Munday, C. J., Fukuzumi, S., Ohkubo, K., Lazarus, M., Maruyama, T., Martin, S. K., Duszenko, M. \& Urade, Y. (2002). J. Exp. Med. 196, 1241-1251.

McCracken, J. A., Carlson, J. C., Glew, M. E., Goding, J. R., Baird, D. T., Green, K. \& Samuelsson, B. (1972). Nat. New Biol. 238, 129134.

Mathe, A. A., Hedqvist, P., Strandberg, K. \& Leslie, C. A. (1977). N. Engl. J. Med. 296, 910-914.

Matthews, R. G. \& Massey, V. (1969). J. Biol. Chem. 244, 17791786.

Meah, Y. \& Massey, V. (2000). Proc. Natl. Acad. Sci. USA, 97, $10733-$ 10738.

Merritt, E. A. \& Murphy, M. E. P. (1994). Acta Cryst. D50, 869873.

Mutayoba, B. M., Meyer, H. H., Osaso, J. \& Gombe, S. (1989). Theriogenology, 32, 545-555.

Narumiya, S., Sugimoto, Y. \& Ushikubi, F. (1999). Physiol. Rev. 79, 1193-1226.

Navaza, J. (2001). Acta Cryst. D57, 1367-1372.

Okano, Y., Inoue, T., Kubata, B. K., Kabututu, Z., Urade, Y., Matsumura, H. \& Kai, Y. (2002). J. Biochem. 132, 859-861.

Oliw, E., Granstrom, E. \& Anggard, E. (1983). Prostaglandins and Related Substances, edited by C. Pace-Asciak \& E. Granstrom, pp. 11-19. Amsterdam: Elesevier Science.

Otwinowski, Z. \& Minor, W. (1997). Methods Enzymol. 276, 307326.

Pak, J. W., Knoke, K. L., Noguera, D. R., Fox, B. G. \& Chambliss, G. H. (2000). Appl. Environ. Microbiol. 66, 4742-4750.

Samuelsson, B. (1979). Harvey Lect. 75, 1-40.

Schaller, F. \& Weiler, E. W. (1997). J. Biol. Chem. 272, 28066-28072.

Schopfer, L. M. \& Massey, V. (1991). Old Yellow Enzyme. Boston: CRC Press.

Snape, J. R., Walkley, N. A., Morby, A. P., Nicklin, S. \& White, G. F. (1997). J. Bacteriol. 179, 7796-7802.

Sugiyama, S., Tokuoka, K., Uchiyama, N., Okamoto, N., Okano, Y., Matsumura, H., Inaka, K., Urade, Y. \& Inoue, T. (2007). Acta Cryst. F63, 896-898.

Vaz, A. D., Chakraborty, S. \& Massey, V. (1995). Biochemistry, 34, 4246-4256.

Warburg, O. \& Christian, W. (1933). Biochem. Z. 266, 377-411.

Watanabe, K., Yoshida, R., Shimizu, T. \& Hayaishi, O. (1985). J. Biol. Chem. 260, 7035-7041.

Williams, R. E., Rathbone, D. A., Scrutton, N. S. \& Bruce, N. C. (2004). Appl. Environ. Microbiol. 70, 3566-3574.

World Health Organization (1990). Weekly Epidemiological Record, Vol. 65, pp. 257-261. Geneva: World Health Organization. 